Francis Edeline

\title{
La sintaxis visual
}

El término sintaxis será tomado aquí en su sentido etimológico de $\sigma u v-\tau \alpha \xi \xi$ sc, es decir, reunir, conjuntar. Se trata, pues, de un sentido generalizado que no corresponde exactamente al de la linguística. En un enunciado visual las unidades asf reunidas son las unidades estructurales descritas en el modelo de Palmer. Por otra parte, hasta en el campo de la lingúística, la investigación actual (Haiman, Bolinger...) muestra que la sintaxis es el nivel donde la iconicidad juega el papel más importante.

Ciertos lingüistas sostienen que la sucesividad (v. gr. la Iineatidad) es el criterio de una sintaxis; esto implica, pues, que no habría sintaxis visual. Sin embargo, esto es una restricción inútil ya que, de todos modos, será necesario describir las relaciones espaciales entre unidades estructurales en la imagen... desde luego con otro nombre. Otra buena razón para considerar la sintaxis visual como una verdadera sintaxis es que presenta las mismas relaciones de subordinación que la sintaxis verbal: coordinación, acoplamiento, etcétera. La diferencia radica en los instrumentos: los morfemas especializados llamados marcadores en el lenguaje, y las simetrías, proximidades, contrastes, encadenamientos... en la imagen. Éstas son esencialmente las herramientas topológicas.

Articulación y sintaxis son confundidas en toda semiótica pues, ya sea que se segmente o se redacte, siempre son unidades las que se descubren o se crean, respectivamente. En el lenguaje existen 
algunas buenas razones para tratarlas por separado, ya que las unidades de nivel diferente se comportan de manera diferente. Pero en la semiótica visual éste no es el caso, y una distinción entre articulación y sintaxis sería inútil.

Combatimos enérgicamente la fórmula corriente "el todo es igual a la suma de sus partes", ya que la palabra "suma" no está definida. De hecho, el proceso mismo que nos permite la segregación nos proporciona a la vez las unidades y las relaciones que los unen, es decir, su sintaxis. Para hacer la "suma", para reconstruir el todo, no basta, entonces, meżclar las partes sin importar cómo.

En numerosos casos (ipero no en todos!) una imagen se presenta sobre una superficie plana y limitada por un marco o algo equivalente. Esto aisla la imagen, de tal suerte que la sintaxis no opera más que al interior del marco. El marco como tal no forma parte del sistema, excepto por su forma y su función de aislante. $\mathrm{Ni}$ su grosor ni la materia de que está hecho son pertinentes. Este modo, usual, de presentación es convencional; por otra parte, esto ha sido refutado por numerosos artistas, en particular por Mondrian, para quien las relaciones entre la imagen y su entorno no solamente son pertinentes sino esenciales.

La sintaxis conlleva una parte de la significación. No es suficiente, entonces, enlistar un repertorio de relaciones espaciales posibles: para que nuestra sintaxis sea útil debe estudiar también el efecto de esas relaciones. Desgraciadamente, estamos muy lejos todavía de una descripción y de una interpretación satisfactorias, fuera de algunos lugares comunes.

Las principales dificultades que encontramos son:

- La fuerte interacción existente entre las unidades y las relaciones que las unen;

- El conjunto forma una red muy compleja; una relación puede ser modificada por otra relación que toca la misma unidad: existe una hipersintaxis compuesta por relaciones en- 
tre relaciones. La significación de una relación dada no es autónoma y cerrada. Como en una tela de araña, desplazar un nudo implica un desplazamiento del conjunto de la tela y su nivelación. Se necesita, por tanto, usar un acercamiento sistémico;

- La estructura jerárquica de Palmer implica que las relaciones estén encadenadas a otras. La hipersintaxis participa igualmente entre los niveles y no solamente en el seno de un nivel.

Se podría adoptar la siguiente definición provisional de sintaxis visual: descripción e interpretación de fodas las relaciones que pueden existir entre las unidades coexistentes de un campo visual (limitado o no).

Factores susceptibles de intervenir en una sintaxis visual

Están tomados de diversos autores y discutidos a título informativo. Su presencia en la discusión no significa que los abordemos por nuestra cuenta, pero es necesario, en esta etapa, no descuidar ninguna posibilidad. Entre los factores se encuentran notablemente:

- LA perCefCión: su importancia ha quedado bien demostrada anteriormente en el marco de una ampliada y modernizada psicología de la Gestalt.

- LOS AFECTOS: su presencia puede parecer extraña. Ha sido propuesta por F. Saint-Martin y consiste en proyecciones subjetivas sobre las cuales volveremos. Aunque fuertemente idiosincrásicas, presentan algunas características recurrentes listadas por Rorschach. 


\section{Mecanismos lingüísticos}

Son mencionados para completar, pues el imperialismo linguístico ha sido una maldición para la semiótica. Hasta un LéviStrauss, con toda su inteligencia, ha sucumbido en ello bajo la influencia de su amigo Jakobson. El simple préstamo o calco de los conceptos linguísticos en el análisis de la imagen puede dar resultados hilarantes: no hay más que leer los artículos de Dora Vallier sobre Malevitch o el libro de su émulo Pierre Rouve sobre Turner...

Fuera del hecho de que D. Vallier confunda saturación y luminancia (luminance), al igual que otros elementos de la percepción, su tesis está basada sobre dos homologías triangulares. El primer triángulo consiste en igualar las vocales con los colores, después las consonantes con las formas (esto, de hecho, no carace de fundamento al nivel sinestésico, luego connotativo). En seguida, asimila el triángulo vocálico al triángulo cromático. Por último, pone una correspondencia semejante entre las formas y las consonantes, como sigue:

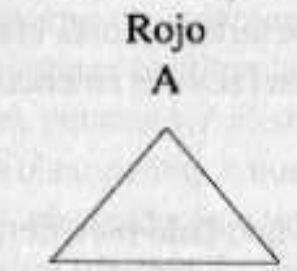

$\mathrm{U}$

Azul
I

Amarillo

(Nota: el verde ha desaparecido)

Así, en este sistema, una franja amarilla «significa» la vocal correspondiente I, etcétera, de manera que todo el sistema fonético de segunda articulación (sonora/sorda, labial/dental, palatal/velar, oclusiva...) puede ser transferido al campo visual. 
L a sintaxis visual será una simple traducción de la fonología linguística. Hasta al admitir esta transposición descabellada, permanecemos en el nivel del significante y no progresamos nada hacia ningún significado. A fin de cuentas liegamos a un tipo de palabra o de frase; pero no avanzamos hacia el sentido asignable a esa frase. Es, sin duda, una fortuna que Dora Vallier haya limitado su empresa a Malevitch...

\section{Interpretación mecánica}

Mucho más serias son las tentativas de utilizar conceptos y métodos prestados por la física y más particularmente por la mecánica, que pueden proporcionar inmediatamente un resultado cifrado. Constituyen la transposición de un problema familiar de mecánica aplicada (mecánica estática). Las unidades visuales son, esta vez, asimiladas a cuerpos físicos, independientes e inmóviles, cuya importancia visual está medida por su peso. Veremos a continuación cómo estos pesos pueden ser valorados.

La seducción inmediata de este acercamiento radica en que concibe la superficie visual como un campo de fuerzas en el que ciertas unidades parecen tener una posición dominante, parecen atraer a otras unidades a su órbita, atraen también nuestros ojos y presentan cualidades de equilibrio o desequilibrio que a la vez son evidentes y difíciles de formular. Todas estas características son fácilmente descritas, medidas, compuestas e interpretadas por un modelo mecanicista. Este tipo de acercamiento ha sido adoptado por varios investigadores del grupo del Profesor S. Marcus. Con mínimas diferencias se encuentra también en J. Guiraud (1986), cuyo método describiré en detalle a continuación.

Una evidente limitación de esta metodología radica en que nosotros no podemos comprobarla más que sobre imágenes suficientemente simples para que se presten al cálculo. No es, entonces, una sorpresa si Mondrian es la elección universal... Ca- 
da caso de un Mondrian es definido por su colorido dominante (según el sistema de Munsell), por su saturación y por un peso correspondiente a su superficie. Los casos son numerados, y los números son reportados en el lugar adecuado sobre el ćrculo de los colores. Se determina, así, el centro de gravedad (baricentro) de éstos, al utilizar las reglas de la mecánica estática. El baricentro es un punto resultante que podrá señalar la posición. Además, los colores compuestos dos a dos, pueden o no formar puntos alineados, o quizá superpuestos, y manifestar así un orden $o$ un desorden. Los resultados son numerosos e interesantes, ya que muestran la existencia de muchas estructuras en Mondrian, y la existencia de un itinerario del pintor de una estructura a otra. La primera estructura concierne a composiciones en tres colores (más el negro) donde uno de los colores es el resultado de los otros dos: se puede describir esta estructura como una mediación. Una segunda estructura pone en obra tres colores saturados, dos colores claros y el negro; los dos puntos resultantes de la composición de los colores saturados y de los colores claros se sitúan sobre una misma línea, por una parte, y por otra el negro: los dos subconjuntos son complementarios y mediados por el negro. Guiraud opone justamente el subconjunto de colores claros (los famosos «azules claros» de Mondrian) al de los colores saturados, en una estructura de equilibrio preciso. En una tercera etapa, Mondrian abandona la referencia del neutro central (agregado gris) para adoptar un alineamiento privilegiado y descentralizado, entre el azul-púrpura y el amarillo. Estos últimos tienen como resultado el tercer color (el rojo), y esta vez los puntos resultantes, en lugar de alinearse, tienen la tendencia a agruparse: acabarán por fusionarse. Desde el punto de vista que nos ocupa aquí, las obras de Mondrian presentan oposiciones coloreadas en dispositivos espaciales que son otras tantas sutiles mediaciones. Éstas son resoluciones in praesentia. Los significados posibles para tales dispositivos son: 
- Mediación de los opuestos

- Neutralidad

- Equilibrio

- Coherencia

Pero como no hay un código, el lugar entre significante y significado queda velado, vago, muy general y, sobre todo, altamente conjetural.

\section{Relaciones topológicas}

La topología es invocada por numerosos autores; en primer lugar es necesario citar a Ferdinan Saint-Martin. En mi opinión, sin embargo, es peligrosa y ya ha dado pie a numerosos malentendidos.

En tanto que teoría matemática, la topología pretende «formalizar la intuición de continuidad en geometría, así como su invariancia (invariance) en las transformaciones» (Wallace, 1957). He aquí algunos conceptos topológicos que podrían interesar a los semióticos:

Relaciones - Cartografía (= aplicación) - Cierre (clausura) Interior - Cercanía - Homeomorfismo - Orden - Convexidad.

A primera vista, la transferencia de estos conceptos parece legítima pues, en efecto, la imagen visual, después de una primera fase de segmentación perceptual, se presenta como una geometría. Pero la topología no puede procurarnos una descripción satisfactoria y completa a causa de dos limitaciones inherentes a esta teoría:

- La topología no tiene métrica;

- La topología no tiene dinámica. 
Vamos a examinar lo que hace falta pensar del empleo de los cuatro conceptos siguientes: continuidad, cercanía, clausura, orden.

Para la continuidad todo parece no tener problema. La continuidad es un concepto que permite solamente cambios graduales. No incumbe únicamente a las líneas, sino también a otras propiedades, espaciales o no. $\mathrm{Y}$ hemos visto que nuestra segmentación visual está basada sobre la percepción de una cualidad translocal, que equivale a una continuidad... Pero nuestra manera humana de tratar las imágenes comienza a apartarse de esta definición cuando introducimos un umbral: así introducimos - ¡creamos! - una discontinuidad ahí donde la topología no vería ninguna. ${ }^{\prime}$

La noción de cercanía es sin duda la más engañosa de todas cuando es utilizada fuera de su ramo. Desgraciadamente, la palabra suscita la idea de proximidad, lo cual no es cercanía en absoluto. La proximidad se refiere a una distancia relativa, medida con una unidad de longitud generalmente extraída del cuerpo humano. Pero antes he precisado que la topología no tiene metrica: de forma que una cercanía puede, a nuestros ojos, ser enorme o minúscula. A continuación presento la definición de cercanía extraída del tratado de Wallace:

Conjunto plano que contiene la figura y tal que todo punto de esta figura sea el centro de un círculo perteneciente por entero a este conjunto.

No hay aquí ya idea de proximidad sino únicamente de continuidad.

\footnotetext{
' Aquí es, por otra parte, el punto de partida de las manipulaciones retóricas. Por ejemplo, ciertos pintores introducen discontinuidades arbitrarias mientras que otros tienden a ocultar discontinuidades reales. Renoir es ejemplar a este respecto: cuando él pinta dos muchachas en un prado cortando flores, casi es imposible localizar el límite entre los personajes y su entorno.
} 
La clausura es un concepto útil pues conduce a nociones de interior y de exterior, de modo que contiene la observación de que no es posible ir de una zona a otra, sino por un número impar de travesaños o cruces. Una línea cerrada puede estar deformada sin perder su carácter de clausura y esto también puede servir de punto de partida a manipulaciones retóricas. ${ }^{2}$

El orden, por el contrario, no puede ser extraído de la topología debido a que sobre una línea continua el orden está preservado por cualquier deformación de la línea... a pesar de que el orden percibido por nosotros puede cambiar totalmente como lo muestra el siguiente dibujo:

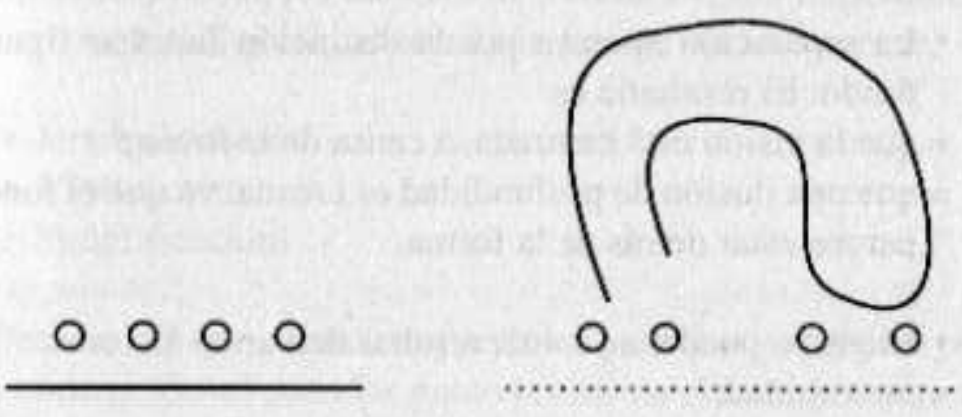
A B C
D
A
D

C

B

Los dos dibujos son topológicamente homomorfos: el orden no sufre cambio. Sin embargo, para nuestra percepción, éste ha cambiado totalmente.

Asf pues, como se ve, terminamos con un resultado decepcionante y la topología probablemente no es el mejor medio para abordar la sintaxis visual, a menos que se tomen numerosas precauciones.

${ }^{2}$ Cfr. los relojes flexibles de Dali o los ectoplasmas de Miró. 
Los factores ligados a la Gestalt (buena forma, imposición...) provienen directamente de los mecanismos perceptivos y resultan de los diversos detectores con que estamos equipados (detectores de motivos y de agrupaciones). Son pues, a priori, pertinentes. La eficacia de estos mecanismos innatos puede en cierta medida ser mejorada por el ejercicio.

Si se examinan cuidadosamente las leyes de la Gestalt se constata que consisten en una sola ley de separación y en una serie de leyes de agrupamiento:

- La separación aparece por la distinción familiar figural fondo. El resultado es

= que la visión está centrada, a causa de la fovea $;^{3}$

= que una ilusión de profundidad es creada, ya que el fondo parece estar detrás de la forma.

- El grupo puede, a su vez, resultar de varios factores:

= proximidad;

= similitud (e indirectamente simetría);

= clausura (donde se reencuentra la topología);

= simplicidad (las «buenas» formas, los «buenos» ángulos...);

$=$ alineamiento

= experiencia pasada .

- Se puede ver que separación y agrupamiento están de hecho correlacionados: una figura no es nada más que un con-

3 Tecnicismo relativo al campo de la percepción: en la zona central de la retina se sitúa la visión fovéale que es la más nítida. Vr. "Index des notions" del Traité da signe visuel del Grupo $\mu$. 
junto de elementos que han sido agrupados y que forman una configuración perceptualmente estable. El aspecto importante es la dinámica del proceso. Estamos obligados a agrupar los elementos visuales. Hay fuerzas que agitan y equilibran el campo visual. Algunos dirán que las fuerzas de atracción y de repulsión son propiedades del sistema perceptivo. Otros tenderán a atribuir estas propiedades al campo mismo percibido (como, por ejemplo, R. Arnheim en su libro The Power of the Centre). Personalmente me inclino por la primera hipotesis.

Incidentalmente, los factores de asociación son importantes para reducir el flujo de información por las operaciones de:

- Jerarquización;

- Abstracción;

- Simplificación.

Pero no hay que considerar jamás las presiones gestálticas como normas. Quizá sean los grados ceros en el sentido retórico. Un artista que se ajustara estrictamente a estas leyes produciría obras absolutamente triviales y carentes de interés: algunos círculos al centro de un cuadro, algunas líneas rectas, colores bien equilibrados... Por el contrario, estas leyes proporcionan sin duda puntos de partida para desviaciones retóricas, para la producción de enunciados visuales originales.

Esto significa que la simple posesión de los mecanismos no es sufieiente. Los factores gestálticos tenderán a minimizar las tensiones residuales, pero deberíamos ser capaces de detectar y medir esas tensiones residuales, que son la esencia misma de la sintaxis visual. Numerosas obras buscan claramente exacerbar estas tensiones residuales.

Como se ha visto, también los conceptos de asociación, proximidad y clausura son suficientemente cercanos a sus corres- 
pondientes en topología para que podamos optar por prescindir de la teoría topológica como tal. ${ }^{4}$

\section{Factores afectivos}

Se trata probablemente de una sugerencia-aunque delicada-de las más interesantes de Saint-Martin: explorar las respuestas afectivas de personas comunes comparadas con las provocadas por imágenes en la prueba de Rorschach. No puedo comentar aquí todas las cuidadosas observaciones de Rorschach en el curso de innumerables sesiones de prueba. He aquí solamente las categorías principales:

- Tendencia irresistible a iconizar;

- Número muy limitado de proyecciones antropocéntricas muy básicas;

- Prisa: el descodificador queda satisfecho rápidamente y se detiene después de haber tomado algunos elementos, descuidando el resto;

- Rechazo del color (sin duda es la observación más sorprendente).

Me pregunto qué tienen que decir los psicólogos de esto. Pienso que aquí se plantea, entre otras cosas, el problema de la lectura adecuada, para retomar el término de Adorno; exactamente como en poesía, música y tantos otros campos.

${ }^{4}$ Deberiamos agregar a los factores gestálticos habituales todos los efectos observados que conciernen al color: equiparación. contraste simultáneo, colores ficticios, tomasolado, efecto de brillo, mezcla (y separación) 6́ptica de las luces (trans. parencia)... 


\section{Restricciones culturales}

La libertad de la sintaxis es, en cierta medida, limitada, restringida por los conjuntos de reglas adoptadas temporalmente por una sociedad dada o un grupo dado. Este fenómeno es un poco parecido a lo que llamamos formateo en informática.

Por ejemplo, formateamos el espacio mediante diversos tipos de perspectivas, formateamos los colores mediante la adopción de paletas seleccionadas, formateamos las formas mediante los estilos. Esto proporciona una especie de rejilla implícita, en referencia a la cual la legibilidad de la imagen aparece enormemente aumentada.

La música conoce juegos de restricciones semejantes bajo el nombre de modos y tonalidades.

\section{Interacciones}

En cuanto a las interacciones entre la sintaxis y las entidades, han sido muy olvidadas hasta ahora. Lo mejor que he encontrado a este propósito es un conjunto de tres reglas aparentemente usadas en el sector de la imagen cinematográfica:

- Asociatividad: toda unidad pide prestada y presta a sus vecinos una parte de su fuerza;

- Precariedad: toda unidad tiende a aniquilar una parte de su especificidad en cuanto entra en relación con otras.

- Conmutabilidad: toda modificación de una unidad tendrá por resultado un cambio en la significación global.

Estas tres reglas recuerdan inevitablemente el ejemplo de la tela de araña ya mencionado. Se podrían agregar aquí reglas concernientes a las homologaciones semánticas en la imagen. Son relaciones de tipo analógico (por oposición digital), por lo tanto continuas y permiten jerarquías entre unidades: 
- La talla de una unidad (con relación al cuadro y con relación a otros) es proporcional a su importancia;

- La brillantez de una unidad (ídem) es igualmente proporcional a su importancia.

En resumen, lo expuesto, que ponía el énfasis sobre los métodos de análisis disponibles para elaborar una sintaxis visual, nos ha puesto en posesión de una serie de instrumentos que también parecen producir una descripción precisa de

- La formación de entidades segmentables;

- La naturaleza de las relaciones espaciales que las vinculan.

Sin embargo, aún nos falta un método que permita una determinación precisa de las fuerzas que operan en el campo visual, salvo en un número muy limitado de casos. Faltan igualmente las directrices para asociar las significaciones a las fuerzas residuales, siempre y cuando estemos convencidos de que en la sintaxis radica una parte de la significación. 